\title{
The Efficacy and Safety of Trehalose in Primary Trabeculectomy with Mitomycin C: A Report of Early Findings
}

\author{
Emine Sen (1) ${ }^{\prime}$ \\ Ufuk Elgin (1D) \\ Osman Ozen $\mathbb{D D}^{2}$ \\ Fikriye Gozde Ozturk (D) ${ }^{3}$ \\ 'University of Health Sciences, Ulucanlar \\ Eye Education and Research Hospital, \\ Glaucoma Department, Ankara, Turkey; \\ ${ }^{2}$ University of Health Sciences, Ulucanlar \\ Eye Education and Research Hospital, \\ Ankara, Turkey; ${ }^{3}$ Unye State Hospital, \\ Ordu, Turkey
}

\begin{abstract}
Objective: To compare bleb morphology and tear tests of glaucoma patients who used trehalose and those who did not use after primary trabeculectomy with mitomycin C (MMC) during the early post-operative period.

Methods: This retrospective study included two groups: Group 1 using Trehalose + hyaluronic acid (THA) after primary trabeculectomy with MMC (n = 19) and Group 2 undergoing primary trabeculectomy with MMC $(\mathrm{n}=16)$. The preoperative and postoperative intraocular pressure (IOP), the results of Schirmer, and tear break-up time tests were analyzed. Postoperative bleb morphology was also evaluated at the 1 st day, and 1 st and 2nd weeks, and 1 st and 2nd months.

Results: There was no statistically significant difference in preoperative IOP, Schirmer test or tear break-up time between groups. The mean horizontal extent of the blebs was significantly wider in Group 1 at the first week $(p=0.02)$. Bleb vascularization was also found to be lower in Group 1 at the second week $(p=0.001)$. The mean bleb height and horizontal extent were significantly higher in Group 1 at the first month $(p=0.02, p=0.03$, respectively). The mean bleb horizontal extent was significantly higher in Group 1 at the second month $(\mathrm{p}=0.03)$.
\end{abstract}

Conclusion: The use of trehalose improved surgical success of primary trabeculectomy with MMC in terms of IOP control, post-operative complications, and bleb morphology during the early postoperative period. Trehalose might contribute to wound healing which led to an ideal bleb.

Keywords: bleb morphology, glaucoma, Schirmer test, trabeculectomy, trehalose

\section{Introduction}

Trehalose, a disaccharide of glucose, is synthetized by many organisms when cells are exposed to stressful conditions, including dehydration, heat, hypoxia. Trehalose has recently been demonstrated to have a number of important properties that indicate its utility in humans. However, it is not synthesized by mammalian cells. The non-toxicity of trehalose allows its administration in humans for extended periods and enables its use in various disease states. ${ }^{1-4}$ Trehalose enables wound healing by protecting cells from oxidative injury. When the injured cornea is treated with trehalose, corneal inflammation, neovascularization, and scar formation are suppressed. $^{2}$ Trehalose decreased cell apoptosis and reduced oxidative, inflammatory and proteolytic activity at the ocular surface in dry eye disease. Trehalose has been suggested as a preservative agent to keep amniotic membranes viable under
Correspondence: Emine Sen

University of Health Sciences, Ulucanla Eye Education and Research Hospital,

Kale Mahallesi, Ulucanlar Caddesi, No: 59, Altındağ, 06250, Ankara, Turkey

Tel +90505 2438I24

Fax +90 3/2 3I24827

Email eminesentr@yahoo.com 
freezing conditions. ${ }^{3}$ Trehalose prevented postoperative fibrous scar formation after ocular surgery, such as glaucoma filtration surgery. ${ }^{2}$ The effect of trehalose on signal transduction induced by $\mathrm{TGFb}$ and its receptors is largely unknown, but trehalose downregulates VEGFR2 and phospho-VEGFR2 expressions in the inflammatory lesion cells. $^{2}$ Takeuchi et $\mathrm{al}^{2}$ showed that trehalose inhibited new angiogenesis or vascular proliferation in wound tissue and trehalose inhibited not only fibroblast proliferation, but also differentiation of fibroblasts into myofibroblasts, causing this to be less pronounced scar formation after trabeculectomy. ${ }^{2}$ Authors thought that this might partially explain the possible mechanism of trehalose action. Besides, this activity might be an indirect result of decreased tissue vascularity. ${ }^{2}$

The most important reason for failure during glaucoma filtering surgery is postoperative intensive scarring. In this surgery, different agents that reduce fibrous proliferation, scarring, and neovascularization in the bleb area and have as few side effects as possible have been searched. Dense and abnormal proliferation of fibroblasts causes intense scarring. The conversion of fibroblasts into myofibroblasts at the wound site has been shown as a reason for the onset of this abnormal scarring. ${ }^{2-4}$ In various in vitro cell culture studies and in vivo animal studies, trehalose has been shown to reduce fibroblast proliferation, to inhibit the conversion of fibroblasts to myofibroblasts, and to reduce conjunctival neovascularization at the site of bleb by inducing apoptosis during the glaucoma filtering surgery. ${ }^{2,4}$ Thus, it is thought that it can prevent excessive scarring in tissues. ${ }^{2-4}$ However, to our knowledge, no clinical study using topical trehalose $3 \%$ solution + hyaluronic acid (HA) $0.15 \%$ (THA) after trabeculectomy performed on humans has been found in the literature so far. Our aim in this study was to determine the effect of postoperative topical THA eyedrop use on bleb morphology and intraocular pressure (IOP) change in glaucoma patients who underwent primary trabeculectomy with mitomycin C (MMC) and to examine its relationship with dry eye parameters.

\section{Methods}

The medical records of 35 eyes of 35 patients in our hospital were evaluated retrospectively. All investigations adhered to the tenets of the Declaration of Helsinki, and the study was approved by the Institutional Review Board and Ethics Committee of Ministry of Health, Ankara Training and Research Hospital (the ethical approval number: Ethics Committee -E-19), since our hospital did not have an ethics committee. All patients gave written informed consent.

This retrospective study consisted of two selected groups: 19 patients using trehalose $3 \%+$ hyaluronic acid (HA) $\quad 0.15 \% \quad$ (Thealoz Duo $^{\circledR}$, Laboratoires Théa, Clermont-Ferrand, France) 4 times a day for 2 months after trabeculectomy with MMC (Group 1) and 16 patients only treated with trabeculectomy with MMC (Group 2). The IOP, results of Schirmer test, tear break-up time (TBUT) and bleb morphology according to Indiana bleb grading system ${ }^{5}$ (bleb height, horizontal extent, vascularization and bleb leakage in Seidel test) were evaluated from the records at the first day, first and second weeks, and first and the second months postoperatively. The number of preoperative antiglaucomatous medication and the type of glaucoma were also recorded.

Trabeculectomy was performed on patients who could not be controlled by medical treatment. Fornixbased trabeculectomy $(4 \times 5 \mathrm{~mm}$ rectangular scleral flap, two permanent sutures with $10 / 0$ monofilament sutures) surgery with MMC $(0.2 \mathrm{mg} / \mathrm{mL}-2$ minutes $)$ was performed by the same surgeon (ES), with the same technique and the same surgical instruments. Conjunctiva was closed with $8 / 0$ vicryl sutures. Topical moxifloxacin hydrochloride $\left(\right.$ Vigamox $^{\circledR} \quad 0.5 \%$ Ophthalmic Solution Alcon) 4 times a day at the first week, prednisolone acetate (Predforte ${ }^{\circledR} \% 1$ Ophthalmic Solution Allergan) 4 times a day at the first month, after that prednisolone was used for 1 month by decreasing the daily dose every week, and cyclopentolate 2 times a day at the first month were used postoperatively. Control measurements of the patient were recorded by a blinded investigator who did not know which group they belonged to.

Exclusion criteria were any corneal diseases, blepharitis, conjunctivitis, eyelid malposition, dry eye disease, previous eye surgery, and lacrimal system abnormalities. Patients who used artificial tear drops before surgery due to dry eye disease were also considered among the exclusion criteria.

All statistical analyses were performed with the SPSS software (SPSS for Windows Version 20.0; SPSS Inc., Chicago, IL). Kolmogorov-Smirnov test was used to determine whether it has a normal distribution. Since the data in the groups conform to the normal distribution, $t$-test was performed in independent groups for the comparisons between the two groups. Chi-squared analysis test was used for the categorical variables. 


\section{Results}

In Group 1 there were 14 female and 5 male patients with a mean age of $56.50 \pm 13.15$ years, while in Group 2 there were 11 female and 5 male patients with a mean age of $56.21 \pm 12.49$ years $(p=0.95, p=0.52$ for age and sex, respectively). There was no statistically significant difference in preoperative IOP, Schirmer test or tear break-up time between groups $(\mathrm{p}=0.66, \mathrm{p}=0.69, \mathrm{p}=0.25$, respectively). Preoperative demographic characteristics, IOP, Schirmer and TBUT values of the patients are shown in Table 1. The number of preoperative antiglaucomatous medications and the types of glaucoma were also not different in both groups ( $\mathrm{p}=0.41$ and $\mathrm{p}=0.65$, respectively).

The mean horizontal extent of the blebs was significantly wider in Group 1 at the first postoperative week $(2.07 \pm 0.62$ vs $1.53 \pm 0.61 \mathrm{~mm}, \mathrm{p}=0.02$ ) (Table 2). The mean bleb vascularization was found to be significantly lower in Group 1 at the second postoperative week $(1.00 \pm 0.65$ vs $2.09 \pm 0.83, \mathrm{p}=0.001)$. The mean bleb height and horizontal extent were significantly higher in Group 1 at the first postoperative month $(\mathrm{p}=0.02$ and $\mathrm{p}=0.03$, respectively). The mean bleb horizontal extent was found to be higher in Group 1 at the second postoperative month $(p=0.03)$. There were no significant differences between both groups at the second month in terms of other parameters ( $p>0.05)$.

Postoperative IOP, Schirmer test, and TBUT values of both groups were shown at Tables 3, Tables 4-5. The Seidel test was not observed postoperatively at all visits.

No postoperative complications were observed.

\section{Discussion}

Trehalose can be safely used as an antigenically inert topical agent. ${ }^{4}$ In the study by Takeuchi et $\mathrm{al}^{4}$ it was demonstrated that when trehalose is used both in vitro (normal human dermal fibroblasts and normal human epidermal keratinocyte cultures) and in vivo (onto rabbit eyes after simple conjunctival incision or trabeculectomy) at a concentration of $5 \%$, it has inhibitory effects specifically on subconjunctival fibrous proliferation. The authors reported that trehalose had strong potential as a topical agent for preventing postoperative fibrous scar formation after trabeculectomy or other ocular surgeries, safely used by patients during the postoperative period. ${ }^{4}$

In the light of this information, we investigated whether topical use of trehalose drop has positive effects on postoperative wound healing, bleb morphology and IOP, as highlighted in the experimental studies mentioned above. To the best knowledge, no clinical studies on humans using topical trehalose after trabeculectomy have been seen in the literature by now. In current study, lower bleb vascularization at the second week, higher bleb height and horizontal extent at the first month, higher bleb horizontal extent at the second month were detected postoperatively. Having a better bleb morphology in the study group during the early postoperative period may be due to its inhibitory effect on subconjunctival fibrous proliferation, as shown in the study of Takeuchi et $\mathrm{al}^{4}$. This effect may increase surgical success by reducing subconjunctival fibrous scarring, which causes bleb failure after trabeculectomy. Although there was no significant difference in terms of IOP, IOP was lower in the study group. This finding may be due to the small number of cases.

In the literature, trehalose-hyaluronic acid, which is used twice a day after cataract surgery, has been shown to reduce the symptoms of dry eye disease at postoperative month 1 follow-up. ${ }^{6}$ Adjuvant treatment with $3 \%$ trehalose after laser-assisted in situ keratomileusis has been shown to improve tear quality parameters during postoperatively

Table I Demographic Characteristics and Preoperative IOP, Schirmer, and TBUT Values of Patients Undergoing Primary Trabeculectomy with MMC

\begin{tabular}{|c|c|c|c|}
\hline & Group I $(n=19)$ & Group $2(n=16)$ & $\mathbf{p}$ \\
\hline Age (years, mean $\pm S D$ ) & $56.50 \pm 13.155$ & $56.21 \pm 12.49$ & $0.95^{*}$ \\
\hline Sex female $(n)$ & 14 & 11 & $0.52^{* *}$ \\
\hline Male (n) & 5 & 5 & \\
\hline IOP $(\mathrm{mmHg}$, mean $\pm \mathrm{SD})$ & $29.44 \pm 7.89$ & $30.79 \pm 9.91$ & $0.66 *$ \\
\hline Schirmer $(\mathrm{mm}$, mean $\pm \mathrm{SD})$ & $9.69 \pm 4.53$ & $9.05 \pm 4.71$ & $0.69 *$ \\
\hline TBUT (second, mean \pm SD) & $4.81 \pm 2.40$ & $5.84 \pm 2.73$ & $0.25^{*}$ \\
\hline
\end{tabular}

Abbreviations: IOP, intraocular pressure; TBUT, tear break up time; $\mathrm{p}^{*}$, independent $t$ test; $\mathrm{p}^{* *}$, chi square test. 
Table 2 Postoperative Bleb Morphology of Patients Undergoing Primary Trabeculectomy with MMC According to Indiana Bleb Grading System ${ }^{5}$ (Bleb Height, Horizontal Extent, Vascularization and Bleb Leakage in Seidel Test)

\begin{tabular}{|c|c|c|c|}
\hline & Group I $(n=19)$ & Group $2(n=16)$ & $\mathbf{p}$ \\
\hline Ist day bleb height & $1.25 \pm 0.68$ & $1.05 \pm 0.23$ & 0.24 \\
\hline Ist day horizontal extent & $1.94 \pm 0.68$ & $\mathrm{I} .47 \pm 0.5 \mathrm{I}$ & 0.03 \\
\hline Ist day bleb vascularization & $2.25 \pm 0.45$ & $2.11 \pm 0.46$ & 0.35 \\
\hline Ist week bleb height & $1.57 \pm 0.65$ & $1.37 \pm 0.49$ & 0.31 \\
\hline Ist week horizontal extent & $2.07 \pm 0.62$ & $1.53 \pm 0.61$ & 0.02 \\
\hline Ist week bleb vascularization & $2.00 \pm 0.11$ & $2.21 \pm 0.71$ & 0.28 \\
\hline 2nd week bleb height & $1.53 \pm 0.52$ & $1.18 \pm 0.41$ & 0.07 \\
\hline 2nd week horizontal extent & $2.13 \pm 0.51$ & $2.00 \pm 0.45$ & 0.49 \\
\hline 2nd week bleb vascularization & $1.00 \pm 0.65$ & $2.09 \pm 0.83$ & 0.001 \\
\hline Ist month bleb height & $1.53 \pm 0.64$ & $1.11 \pm 0.32$ & 0.02 \\
\hline Ist month horizontal extent & $2.20 \pm 0.4 \mathrm{I}$ & $\mathrm{I} .83 \pm 0.5 \mathrm{I}$ & 0.03 \\
\hline Ist month bleb vascularization & $0.93 \pm 0.59$ & $1.11 \pm 0.96$ & 0.53 \\
\hline 2nd month bleb Height & $2.20 \pm 2.21$ & $1.35 \pm 0.49$ & 0.13 \\
\hline 2nd month horizontal extent & $2.20 \pm 0.4 I$ & $1.82 \pm 0.53$ & 0.03 \\
\hline 2nd month bleb vascularization & $0.80 \pm 0.56$ & $1.19 \pm 0.77$ & 0.050 \\
\hline
\end{tabular}

Notes: P: independent sample $t$ test, values less than 0.05 were considered significant and shown as bold. The Seidel test was not observed postoperatively at all visits.

Table 3 Postoperative IOP

\begin{tabular}{|l|c|c|c|}
\hline Group (n:Number) & Group I (n: 19) & Group 2 (n: 16) & P \\
\hline Ist day IOP $(\mathrm{mmHg}$, mean $\pm S D)$ & $11.56 \pm 6.48$ & $11.79 \pm 4.50$ & 0.90 \\
\hline Ist week IOP $(\mathrm{mmHg}$, mean $\pm S D)$ & $10.53 \pm 3.54$ & $12.16 \pm 2.11$ & 0.11 \\
\hline 2nd week IOP $(\mathrm{mmHg}$, mean $\pm S D)$ & $10.86 \pm 3.25$ & $12.31 \pm 2.09$ & 0.16 \\
\hline Ist month IOP $(\mathrm{mmHg}$, mean $\pm S D)$ & $12.50 \pm 3.21$ & $12.22 \pm 1.86$ & 0.76 \\
\hline 2nd month IOP $(\mathrm{mmHg}$, mean $\pm S D)$ & $12.29 \pm 4.19$ & $12.41 \pm 1.91$ & $0.9 \mid$ \\
\hline
\end{tabular}

Abbreviations: IOP, intraocular pressure; $\mathrm{P}$, independent sample $t$ test.

Table 4 Postoperative Schirmer Values

\begin{tabular}{|c|c|c|c|}
\hline & Group I $(n=19)$ & Group $2(n=16)$ & $\mathbf{p}$ \\
\hline I st day schirmer (mm, mean $\pm \mathrm{SD})$ & $18.75 \pm 6.39$ & $16.00 \pm 6.28$ & 0.21 \\
\hline Ist week schirmer (mm, mean $\pm S D)$ & $12.20 \pm 6.48$ & $10.26 \pm 4.99$ & 0.33 \\
\hline 2nd week schirmer (mm, mean $\pm S D)$ & $12.00 \pm 5.49$ & $8.81 \pm 3.83$ & 0.06 \\
\hline I st month schirmer (mm, mean $\pm \mathrm{SD})$ & $11.56 \pm 6.07$ & $9.28 \pm 3.89$ & 0.18 \\
\hline 2nd month Schirmer (mm, mean $\pm S D)$ & $11.44 \pm 5.18$ & $9.35 \pm 1.73$ & 0.12 \\
\hline
\end{tabular}

Note: P: independent sample $t$ test. 
Table 5 Postoperative TBUT Values

\begin{tabular}{|c|c|c|c|}
\hline & Group I $(n=19)$ & Group $2(n=16)$ & $\mathbf{p}$ \\
\hline Ist day TBUT (second, mean $\pm S D$ ) & $5.56 \pm 1.63$ & $6.63 \pm 2.43$ & 0.14 \\
\hline Ist week TBUT (second, mean \pm SD) & $5.33 \pm 1.11$ & $6.11 \pm 2.26$ & 0.24 \\
\hline 2nd week TBUT (second, mean $\pm S D$ ) & $5.06 \pm 1.29$ & $4.94 \pm 2.08$ & 0.84 \\
\hline Ist month TBUT (second, mean \pm SD) & $5.19 \pm 1.17$ & $5.56 \pm 1.50$ & 0.08 \\
\hline 2nd month TBUT (second, mean $\pm S D$ ) & $5.69 \pm 1.09$ & $6.47 \pm 2.43$ & 0.24 \\
\hline
\end{tabular}

Abbreviations: TBUT, tear break up time; P, independent sample $t$ test.

90 days. ${ }^{7}$ It has been shown in clinical studies that trehalose also improves the symptoms of dry eye disease. ${ }^{6-9}$ In this study, we evaluated the dry eye parameters in patients using topical Trehalose at a concentration of $3 \%$ as four times a day postoperatively after trabeculectomy. Although the Schirmer test value was higher at the $1 \mathrm{st}$ and 2nd weeks in the study group, no significant difference was detected between both groups. The ocular surface disease has been demonstrated to be observed in 49-59\% of glaucoma patients receiving topical medical treatment. It has also been reported that dry eye reduces the success of glaucoma surgery. ${ }^{10-15}$ Therefore, we tried to ensure that the effect of dry eye on surgical success was similar in both groups by enrolling the patients who had similar Schirmer test and TBUT in both groups before the surgery. The effects secondary to toxicity due to glaucoma drug may have started to improve as we discontinued all antiglaucomatous drugs after trabeculectomy. In our study, Schirmer test value was higher in the study group postoperatively especially at 2 nd week. In our opinion, this positive effect of THA on the tear tests may be related to the Hyaluronic acid.

The limitations of our study are that it was retrospective, the number of patients was relatively small, and the follow-up time was short. Bleb morphology could be evaluated not only by biomicroscopy but also by objective methods such as anterior segment optical coherence tomography (OCT) or in vivo confocal biomicroscopy. ${ }^{16}$ It would also be more appropriate to select patients who have never used drugs to exclude possible ocular surface toxicity of antiglaucomatous drugs. However, as we know, the initial treatment of glaucoma is usually medical treatment. Therefore, patients are led to surgical treatment in cases where medical treatment is insufficient after starting medical treatment. In addition, as our hospital is a tertiary treatment center, patients who have previously been started on medication and whose medical treatment was not considered sufficient are referred to us for surgical treatment. Therefore, all of our patients were using the medication before surgery. However, the remarkable aspect of this study is that trehalose increased the Schirmer test values after trabeculectomy more than the control group, and it may help patients' tear functions return to normal. We believe that this will have a positive effect on the patient's quality of life and surgical success in the long term.

In conclusion, the use of trehalose improved surgical success of primary trabeculectomy with MMC, with better bleb morphology. No significant difference was found in terms of tear parameters and IOP between both groups during early postoperative period. However, prospective studies with long follow-up periods are necessary in order to better consolidate our results.

\section{Disclosure}

This article was presented as a poster at the 14th EGS Congress, 12-13 Dec 2020.

The authors declare that there is no conflict of interest regarding the publication of this paper.

\section{References}

1. Cejka C, Kubinova S, Cejkova J. Trehalose in ophthalmology. Histol Histopathol. 2019;34:611-618. doi:10.14670/HH-18-082

2. Takeuchi K, Nakazawa M, Ebina Y. Effects of trehalose on VEGF-stimulated angiogenesis and myofibroblast proliferation: implications for glaucoma filtration surgery. Invest Ophthalmol Vis Sci. 2011;52:6987-6993. doi:10.1167/iovs.11-7478

3. Nakamura T, Sekiyama E, Takaoka $M$, et al. The use of trehalose-treated freeze-dried amniotic membrane for ocular surface reconstruction. Biomaterials. 2008;29:3729-3737. doi:10.1016/j. biomaterials.2008.05.023

4. Takeuchi K, Nakazawa M, Ebina Y, et al. Inhibitory effects of trehalose on fibroblast proliferation and implications for ocular surgery. Exp Eye Res. 2010;91:567-577. doi:10.1016/j.exer.2010.07.002 
5. Cantor LB, Mantravadi A, WuDunn D, Swamynathan K, Cortes A. Morphologic classification of filtering blebs after glaucoma filtration surgery: the Indiana bleb appearance grading scale. J Glaucoma. 2003;12:266-271. doi:10.1097/00061198-200306000-00015

6. Caretti L, La Gloria Valerio A, Piermarocchi R, et al. Efficacy of carbomer sodium hyaluronate trehalose vs hyaluronic acid to improve tear film instability and ocular surface discomfort after cataract surgery. Clin Ophthalmol. 2019;13:1157-1163. doi:10.2147/OPTH. S208256

7. Orobia AJM, Pascual PC, Bescós JC, et al. Effects of $3 \%$ trehalose as an adjuvant treatment after LASIK. Clin Ophthalmol. 2017;11:347-353. doi:10.2147/OPTH.S125203

8. Pinto-Bonilla JC, Del Olmo-Jimeno A, Llovet-Osuna F, HernandezGalilea E. A randomized crossover study comparing trehalose/hyaluronate eyedrops and standard treatment: patient satisfaction in the treatment of dry eye syndrome. Ther Clin Risk Manag. 2015;11:595-603. doi:10.2147/TCRM.S77091

9. Chiambaretta F, Doan S, Labetoulle M, et al. HA-trehalose Study Group. A randomized, controlled study of the efficacy and safety of a new eye drop formulation for moderate to severe dry eye syndrome. Eur J Ophthalmol. 2017;27:1-9. doi:10.5301/ejo.5000836

10. Ji H, Zhu Y, Zhang Y, et al. Dry eye disease in patients with functioning filtering blebs after trabeculectomy. PLoS One. 2016;11: e0152696. doi:10.1371/journal.pone.0152696
11. Lee S-Y, Wong TT, Chua J, et al. Effect of chronic anti-glaucoma medications and trabeculectomy on tear osmolarity. Eye (Lond). 2013;27:1142-1150. doi:10.1038/eye.2013.144

12. Lam J, Wong TT, Tong L. Ocular surface disease in posttrabeculectomy/mitomycin C patients. Clin Ophthalmol. 2015;9:187-191. doi:10.2147/OPTH.S70721

13. Zhang X, Vadoothker S, Munir WM, Saeedi O. Ocular surface disease and glaucoma medications: a clinical approach. Eye Contact Lens. 2019;45:11-18. doi:10.1097/ICL.0000000000000544

14. Leung EW, Medeiros FA, Weinreb RN. Prevalence of ocular surface disease in glaucoma patients. $J$ Glaucoma. 2008;17:350-355. doi:10.1097/IJG.0b013e31815c5f4f

15. Fechtner RD, Godfrey DG, Budenz D, Stewart JA, Stewart WC, Jasek MC. Prevalence of ocular surface complaints in patients with glaucoma using topical intraocular pressure-lowering medications. Cornea. 2010;29:618-621. doi:10.1097/ICO.0b013e3181c325b2

16. Yılmaz SG, Değirmenci C, Palamar M, Yağcı A. Evaluation of filtering bleb function after trabeculectomy with mitomycin $\mathrm{c}$ using biomicroscopy, anterior segment optical coherence tomography and in vivo confocal microscopy. Turk $J$ Ophthalmol. 2015;45 (4):132-137. doi:10.4274/tjo.29052
Clinical Ophthalmology

\section{Publish your work in this journal}

Clinical Ophthalmology is an international, peer-reviewed journal covering all subspecialties within ophthalmology. Key topics include: Optometry; Visual science; Pharmacology and drug therapy in eye diseases; Basic Sciences; Primary and Secondary eye care; Patient Safety and Quality of Care Improvements. This journal is indexed on PubMed

\section{Dovepress}

Central and CAS, and is the official journal of The Society of Clinical Ophthalmology (SCO). The manuscript management system is completely online and includes a very quick and fair peer-review system, which is all easy to use. Visit http://www.dovepress.com/ testimonials.php to read real quotes from published authors. 